\title{
The Reform and Innovation of Environmental Law Teaching Under the Training Mode of Applied Legal Talents
}

\author{
DongLin $\mathrm{XU}^{1, *}$ \\ ${ }^{I}$ School of Law, MinJiang University, FuZhou, FuJian, China \\ *18492262@qq.com
}

\begin{abstract}
As one of the core courses of law undergraduate, Environmental Law has its unique disciplinary characteristics. Under the training mode of application-oriented legal talents, the teaching of Environmental Law is faced with some difficulties, such as less class hours, multiple and strong overlapping contents, and the traditional teaching methods are difficult to adapt to the requirements of new-type personnel training. By clarifying the relationship between the training of application-oriented legal talents and the National Judicial Examination, we can explore better teaching methods and contents to meet the needs of application-oriented legal personnel training.
\end{abstract}

Keywords: Applied legal talents, Teaching of Environmental Law, Reform, Innovation

\section{应用型法律人才培养模式下《环境法学》教学改革 与创新}

许冬琳 ${ }^{1, a}$

1 闽江学院法学院, 福州, 福建, 中国

a18492262@qq.com

内容摘要

环境法作为法学本科核心课程之一, 有其独特的学科特点。在应用型法律人才培养模式下, 环境法教 学面临课时少、内容多且交叉性强、传统教学方法难以适应新型人才培养要求等困境。通过厘清应用 型法律人才培养与法律职业资格考试之间的关系, 进而寻求环境法教学方法、教学内容等方面的改进 措施，以适应应用型法律人才培养的需求。

关键词: 应用型法律人才 环境法教学 改革 创新

\section{1. 引言}

1979 年《中华人民共和国环境保护法（试行）》颁 布实施, 推动了环境法理论研究的发展, 环境法律实务 工作也日益增加, 奠定了环境法成为独立部门法的理论 和实践基础。《环境法》作为法学专业本科课程于 20 世 纪 80 年代初开始在国内部分高校的法律系中开设。 1984 年国家教委颁布的《综合大学法律系法律专业教学 计划》将环境法列为法学专业本科教学的专业选修课, 1985 年制定的《经济法专业教学计划》将环境法和自然 资源法两门课程列为经济法专业的专业必修课, 1997 年国家教委公布的二级学科中就包括了 “环境与资源保 护法学”, 2007 年环境与资源保护法学被教育部高校法
学学科教学指导委员会增列为法学核心课程。 ${ }^{[1]}$ 此后, 这一新兴的部门法, 迎来了课程教学与学术研究蓬勃发 展的盛况。近年来, 高校的人才培养目标业已转向培养 应用型人才, 高校法学专业的人才培养目标也有了新的 目标和导向, 即应用型法律人才培养, 培养适应社会实 际需求的法律人才, 这为环境法教学的改革与创新提出 了新的研究课题。

\section{2. 《环境法学》的学科特点}

国际上普遍将“环境与资源保护法”称为“环境法”, 目前我国的法学本科培养方案与教材中对这一学科的 称谓各不相同，大致有 “环境与资源保护法学”、“环 境保护法学”、“环境资源法”等。作为新兴的法学学 
科，环境法有其显著的学科特点，主要表现在一下三方 面:

其一，与传统部门法学科有密切的联系。例如, 环 境损害救济中涉及的环境侵权、自然资源有偿使用, 以 及环境公益诉讼等问题, 属于民法范畴; 污染防治以及 自然资源保护则属于行政法范畴; 危害环境犯罪又是刑 法范畴; 国际环境法则属于国际法范畴。然而, 现代法 律体系中的环境法, 作为独立的法律部门, 已具有自身 的特点, 并非传统部门法的简单集合, 是为治理现代环 境问题、实现可持续发展而产生和发展的新型部门法; 同时环境法也综合运用了传统部门法的法律措施，调整 广泛而复杂的社会关系。

其二, 环境法是生态环境科学与法结合的产物。环 境法对环境保护和利用社会关系的调整, 是以环境科学 为基础的, 必须符合环境与生态科学的基本规律和基本 要求。在环境法中, 环境标准、技术性规范等法律规范 往往是用法律语言表现的环境科学, 通过赋予环境标准 等科学名词和术语以法律定义, 使其具有法律效力。此 外, 环境科学也为环境执法和司法提供技术保障。值得 关注的是, 环境法虽以环境科学为基石, 但环境法有其 自身的价值取向和立法目的, 与环境科学的技术性规范 有本质区别, 即环境法追求公平、正义、可持续发展等 人文价值。

其三, 环境法的公益属性。环境法除了公平、正义 等传统价值取向外, 还有其特有的价值取向, 即保护全 人类的共同利益、促进经济与社会的可持续发展, 具有 明显的社会法特征, 并非传统人本主义价值观的公法或 私法所能涵盖。

\section{3. 《环境法学》教学的困境}

与法学其他分支学科相比, 环境法的内容更加庞 杂, 与更多相关学科交叉, 尤其是在总论部分, 边缘化、 交叉性的知识占有较大比重。 ${ }^{[4]}$ 因此, 在环境法的教学 中, 帮助学生掌握环境法的基本理论, 同时能够将理论 联系实际，培养应用型法律人才，依然面临诸多困境。

\section{1. 庞杂的教学内容与有限课时的矛盾}

从现有教材的体系看, 环境法的教学内容一般包 括：总论、环境污染防治法、自然资源保护法、环境损 害救济法、危害环境犯罪、国际环境法, 周珂主编的《环 境与资源保护法》（2018 年版）共 60. 4 万字，共 382 页; 汪劲的《环境法学》（2017 年版）共 54.9 万字, 共 411 页, 可见 《环境法》课程内容多且庞杂。反观目 前高校法学本科专业的课程设置, 有 $70 \%$ 以上开设法学 专业的高校开设了环境与资源保护法课程, 其中 $48.6 \%$ 设置为必修课, 大部分高校课时设置为 32 学时, 最短 的为 16 学时。 ${ }^{[5]}$ 有限的课时设置与庞杂的教学内容之 间的矛盾显而易见, 在有限的学时中, 怎样平衡授课与 实训之间的课时安排, 怎样完成教学内容并能适当深入
展开, 怎样实现环境法的教学目的、达到教学效果, 是 环境法教学中面临的首要困境。

\section{2. 争议性的学术观点与教材有机结合的困 境}

环境法作为年轻的部门法, 其理论和体系都存在多 种学术观点, 也存在诸多争议, 每一本教材对某一具体 理论问题所持的观点也并不尽相同，譬如环境法的调整 对象，蔡守秋主编的《环境资源法教程》认为环境法的 调整对象是人与自然的关系、与环境资源有关的人与人 的关系; ${ }^{[6]}$ 周珂主编的《环境与资源保护法》则认为环 境法的调整对象是人与人之间的社会关系，包括基于国 家环境行政管理而产生的社会关系、平等主体之间基于 环境和自然资源而产生的社会关系、社会工作参与环境 保护与环境管理而产生的社会关系、基于国家环境权益 保障而产生的社会关系; ${ }^{[7]}$ 汪劲的《环境法》将环境法 的调整对象表述为 “人类在从事环境利用行为过程中形 成的环境利用关系”。 ${ }^{[8]}$ 在环境法总论部分, 环境法的 调整对象是不可回避的授课内容, 怎样让学生了解不同 的学术观点及其争议的焦点, 进而探寻总论部分的法理 基础与分论部分的内在逻辑, 是《环境法》尤其是总论 部分教学中的难点。

\section{3. 《环境法学》教学与法律职业资格考试的 关系有待进一步厘清}

根据 2018 年司法部颁布的《国家统一法律职业资 格考试实施办法》的规定，本科应届毕业生可参加国家 统一法律职业资格考试, 而环境资源法考题在 2018 年 法律职业资格考试的客观题中仅占 5 分, ${ }^{[9]}$ 占客观题总 分 (300 分) 的 1.67\%, 相较民法、刑法等传统法律部 门, 显得无足轻重。然而在实务中, 与环境、自然资源 有关的诉公案件量却很庞大，2019 年 11 月在中国裁判 文书网以 “环境污染” 为关键词搜索，显示裁判书多达 32081 件, 环境公益诉讼裁判文书 274 件。可以见得, 法律实务中对于环境法人才的需求日益增长, 实务中涉 及的环境法理论并不局限于法律职业资格考试的内容, 环境法的课程教学恰好填补了资格考试中的不足。如何 培养学生学习环境法的热情和积极性, 是环境法教学中 值得探讨的命题; 而厘清应试型法律教育与应用型法律 人才培养之关系, 是法学本科培养规划中的一个重要命 题。

\section{4. 传统教学方法难以适应应用型法律人才 培养的困境}

我国法学本科课堂教学主要采用传统的以教材、课 堂和教师为中心的授课方法, 考试形式以书面考核为 主，而这一授课方式业已受到来自 “慕课” 等网络课程 
的极大挑战, 一方面, 网络课程的创新性、灵活性迎合 了学生对于多样化教学模式的需求, “慕课” 的开放性 更使学生有机会获取名校名师的授课, 有利于扩展学生 的视野, 也有利于学生深入地掌握理论知识点; 而另一 方面, 慕课、网校的 “学习包” 和 “名师课程” 等各种 法学在线课程也激发学生对于实用性、生动性、互动性 课堂的需求, 传统教学方法在生动性和互动性上的短 板、本科实践教学的不足都在网课时代凸显出来。

\section{4. 《环境法学》教学模式的探索与改革}

\section{1. 厘清应用型法律人才培养与应试型法律 教育之关系}

首先, 应用型法律人才培养注重学生应用和实践能 力的培养, 但并不等同于考试培训或法律职业培训, 将 法律职业资格考试作为法学本科人才培养的风向标、指 挥棒, 实际上片面地将法律人才局限于法律职业, 而忽 视了社会对法律人才的多种需求。 ${ }^{[10]}$ 法学本科毕业生就 业空间呈现出多样化的趋势, 而从事法律职业的仅仅是 是其中的一部分, 应用型法律人才的培养应关注社会各 领域对法律人才的需求, 而不是仅仅是培养司法、律师 人才。其次, 法律是由科学、精细的概念、原则和规则 构成的, 法学学科亦是复杂且技巧性极强的学科, 通过 法学本科阶段的课程, 让学生掌握概念、原则、规则等 理论, 培养学生法律思维能力和逻辑分析能力, 能够 “像 法律人一样思考”, 是在工作实践中掌握诉讼等实务技 巧的前提和基础, 否则实践就是 “空中楼阁” 。 ${ }^{[11]}$ 因此, 法律院系在本科专业的课程设置上, 不应以法律职业资 格考试为导向, 更不应以法律职业资格考试为依据缩减 法律职业资格考试中比重较少学科的学分和课时。最 后, 在保证法学本科教学目标实现的前提下, 重视法律 职业资格考试。根据《2019 年中国大学生就业报告》显 示, 法学专业被列为 “本科就业专业预警” 的红牌专业 之一, 失业量较大, 就业率较低, 因此各类职业资格考 试成为法学本科毕业生就业的重要敲门砖, 其中法律职 业资格证书, 吸引了 $90 \%$ 以上的在校法学专业学生。而 法律职业资格考试难度大、通过率低、含金量高, 在本 科教学工作中也不应忽视这一考试。在环境法教学中, 应在教学目标、教材内容与法律职业资格考试中的环境 法考点三者之间找到连接点, 通过对 (原司法考试) 真 题、习题、案例的讲解, 在对本科环境法教学内容深入 和完善的同时, 亦帮助学生掌握资格考试的知识点。

\section{2. 完善课程设置, 改革教学方法}

在课程设置上，应在确保基础理论课程的基础上， 兼顾法律实务课程。近年来, 各高校法学院开始重视实 践性课程的比重, 开设了实践课程和法律实务课程, 环 境法是一门交叉性极强的法律, 环境执法和司法也具有
相当的交叉性和专业性，高校教师以教学、科研为主业， 要在环境法教学中准确把握执法与司法实践、实现理论 与实践的有效结合，有相当的难度。聘请实务界的律师、 法官、检察官、执法部门工作人员作为环境法课程的兼 职教师、客座教授, 讲授环境法实务问题, 对学生掌握 环境法的基本制度、污染防治法、环境法律责任等理论 均有良好的裨益, 同时也开拓了学生的视野和思维。值 得一提的是, 引入环境法实务课程内容, 并不意味着把 重心转移到实务课程中, 法学本科教育中, 过度对本科 生进行法律职业培训, 在限制学生的思维、创造力的同 时, 也不利于基础法学理论的掌握。庭审技巧、诉讼技 巧等法律实务经验和职业技能必须要在法律实务工作 中累积, 对于法学本科学生而言, 一味追求此类技巧和 经验的提升显然是不切

实际的。

在教学方法上, 首先, 打破传统的授课为主的教学 方法, 引入案例教学法、实地考察教学法等新兴教学方 法, 引导学生带着问题分析案例、实地考察海洋馆、饮 用水源取水口、垃圾处理（填埋）场等，在案例中和实 践中思考探索, 寻求解决问题的途径, 并在案例和实地 考察中深入理解和掌握水资源保护法、海洋环境保护 法、固体废物污染防治法等教学内容。其次, 课堂上也 应增强师生互动、“翻转课堂”, 调动学生主动性和积 极性。以总论部分为例, 针对具有争议性的学术观点, 引导学生阅读文献资料, 采用研究报告或小组讨论汇报 等形式, 阐述不同的学术观点, 并发表个人见解, 以加 深对理论的理解和掌握。最后, 在考试形式上, 应注重 阶段性和灵活性。阶段性的考查可以了解学生掌握知识 点的程度, 有助于教师及时根据考查情况答疑解惑; 考 查方式可以多样化, 可综合学生各方面的成绩作出形成 性评价, 考查形式包括案例讨论或模拟法庭的参与度、 实地考察的调研报告和汇报小结、作业和小测的成绩 等。

\section{5. 结语}

在培养应用型法律人才的目标下, 法学本科专业的 环境法教学也遭遇了挑战, 对法学本科专业课程设置的 重新审视、对环境法教学方法的改进, 无疑是环境法教 学突破与完善的必要途径。

\section{References}

[1][5]Wu P., Deng Y.P.,(2016)Reform and Innovation of Environmental Law Education in Universities from the Perspective of Ecological Civilization,

Journal of East China Institute of Technology, 4:370-373.

[2] Wang J.(2017)Environmental Law, Peking University Press,Peking.Introduction.

[3]Zhou K.(2018)Environment and Resource Protection 
Law.China Renmin University Press (CRUP), Peking. Pp17-18.

[4] Zhou K. (2018) Environment and Resource Protection Law.China Renmin University Press (CRUP), Peking. Introduction.

[6]Cai S.Q.(2016)Text and Materials of the Environment and Resources Law.

Higher Education Press,Peking.pp67

[7] Zhou K.(2018)Environment and Resource Protection Law.China Renmin University Press (CRUP), Peking. Pp22.

[8] Wang J. (2017) Environmental Law, Peking University Press,Peking.pp23

[9]XiLv.(2018)A detailed explanation of the subjective and objective structure of the 2018

Legal professional qualification examination,https://www.sohu.com/a/244567236_1001278 51

[10] Yang H.,Wei J.X.,(2018)Research on the Reform of Law Undergraduate Education under the Background of National Judicial Examination,Social Scientist,2:114-118.

[11]Cheng X.Y.,(2018).The Reform of Law Undergraduate Education and the Improvement of Talent Standard from the Perspective of Social Function Differentiation,

Journal of Gansu Administration Institute,5:117-128. 